\title{
PROBLEMATA ШЬOBVHW
}

CONFERÊNCIA

\section{SOBRE $O$ CAPITAL DE MARX: PARA TRANSFORMAR COM SENTIDO É PRECISO COMPREENDER OS SENTIDOS ${ }^{1}$}

\section{ABOUT MARX'S CAPITAL: TO TRANSFORM WITH MEANING IT IS NECESSARY TO UNDERSTAND THE MEANINGS}

\author{
José Barata-Moura ${ }^{2}$ \\ Recebido em: 07/2019 \\ Aprovado em: 11/2019
}

\begin{abstract}
Resumo: Este artigo consiste em uma exposição elaborada a partir da associação entre aspectos históricos e teóricos atinentes à produção d' $O$ capital, realizada a partir da urdidura entre datas e conteúdos que articulam o significado crítico da teoria e a sua relevância, com o seu sentido político de transformar e superar a sociedade capitalista. Mapeia conceitos a partir dos seus encontros e desencontros epistemológicos estabelecidos entre a dialéctica hegeliana e a dialéctica do "materialismo ontológico", à medida que esmiúça os sentidos filosófico e político da obra. Oferece uma chave heurística para a decifração da obra enquanto um empreendimento não apenas científico, mas sobretudo político e comprometido com a luta pelo socialismo. [Resumo do editor]. Palavras-chave: Marx; $O$ capital; dialéctica; materialismo; socialismo.
\end{abstract}

\begin{abstract}
This article consists of an exposition elaborated from the association between historical and theoretical aspects related to the production of Capital, made from the warp between dates and contents that articulate the critical meaning of the theory and its relevance, with its political sense to transform and overcome capitalist society. It maps concepts from the epistemological encounters and disagreements established between the Hegelian dialectic and the dialectic of "ontological materialism" as it explores the philosophical and political meanings of the work. It offers a heuristic key to the deciphering of the work as an enterprise not only scientific, but above all political and committed to the struggle for socialism. [Editor's abstract].
\end{abstract}

Keywords: Marx; Capital; dialectic; materialism; socialism.

\footnotetext{
${ }^{1}$ Este texto, redigido em Lisboa nos meses de julho e agosto de 2017, corresponde a uma conferência realizada pelo autor em vista dos 150 anos da obra magna de Marx e originalmente intitulada "Num dos aniversários de $O$ capital". O título da presente edição foi estabelecido pelos organizadores. Alguns parágrafos menores e com mesmo foco foram unidos. Manteve-se, contudo, o estilo da numeração original indicada por parágrafos. [N. dos editores].

${ }^{2}$ Professor emérito de Filosofia da Faculdade de Letras e ex-reitor da Universidade de Lisboa. Foi vicepresidente da Sociedade Internacional Hegel-Marx para o Pensar Dialéctico (Internationale Gesellschaft HegelMarx für dialektisches Denken) e é membro efectivo da Academia das Ciências de Lisboa.
} 


\section{§ 1. Datas}

A primeira edição do Livro Primeiro de $_{\text {capital }^{3}}$ saiu em Hamburgo, na casa de Otto Meissner, com alta probabilidade, a 11 de Setembro de $1867^{4}$. Está, portanto, prestes a perfazer 150 anos. Em 1872-1873, apareceu - com uma nova repartição por capítulos, alterações redaccionais, e aditamentos - uma "segunda edição melhorada" (zweite verbesserte Auflage) do Livro Primeiro ${ }^{5}$. (Para uma fixação do texto, nas suas variantes, deverá ter-se igualmente em conta a terceira edição de $1883^{6}$, e a quarta de $1890^{7}$ ).

O capital não se limita, porém, ao Livro Primeiro. No formato canónico que hoje lhe conhecemos, a obra compõe-se de dois Livros mais, que foram preparados para a publicação por Engels, a partir do espólio manuscrito que Marx deixou ${ }^{8}$. Sairam em 1885 e 1894, respectivamente ${ }^{9}$. Esta distribuição em três Livros foi aquela que historicamente acabou por se verificar. Mas teve também uma "pré-história", recheada de incidentes no que respeita ao planeamento projectado.

Para o final dos anos 50, Marx imaginava organizar a sua "crítica das categorias económicas" (Kritik der ökonomischen Kategorien) - onde "o sistema da economia burguesa" (das System der bürgerlichen Ökonomie) irá surgir "criticamente exposto" (kritisch dargestellt) -, em seis Livros ${ }^{10}$. (Esta alteração de "planos" deu origem a uma rica literatura

\footnotetext{
${ }^{3}$ Cf. Karl Marx, Das Kapital. Kritik der politischen Ökonomie. Erster Band. Hamburg 1867; Marx-Engels Gesamtausgabe, ed. Günter Heyden e Anatoli Jegorow (doravante: MEGA²), Berlin, Dietz Verlag, 1983 , vol. II/5.

${ }^{4}$ A datação tradicional da vinda a público apresenta pequenas variações: cerca de 2 de Setembro: Karl Marx. Chronik seines Lebens in Einzeldaten (1934), ed. Vladímir Viktoróvitch Adorátski, reprod. Frankfurt am Main, Makol Verlag, 1971, p. 260; "no começo de Setembro" (au début de Septembre): Maximilien Rubel, "Chronologie" in Marx, Oeuvres. Économie, ed. M. Rubel (doravante: O), Paris, Éditions Gallimard/Bibliothèque de la Pléiade, 1965, vol. I, p. CXXXIII; 14 de Setembro: Karl Marx - Friedrich Engels Werke, ed. IML (doravante: MEW), Berlin, Dietz Verlag, 1973, vol. 16, p. 722. Para uma correcção das datas anteriormente propostas, veja-se: Eike Kopf, "Wann erschien das erste Band des 'Kapitals' von Karl Marx tatsächlich?”, Beiträge zur Marx-Engels Forschung, Berlin, 3 (1978), pp. 81-91.

${ }^{5}$ Cf. Marx, Das Kapital. Kritik der politischen Ökonomie. Erster Band. Hamburg 1872; MEGA ${ }^{2}$, vol. II/6, pp. 57-719.

${ }^{6}$ Cf. Marx, Das Kapital. Kritik der politischen Ökonomie. Erster Band. Hamburg 1883; MEGA², vol. II/8, pp. 37-729.

${ }^{7}$ Cf. Marx, Das Kapital. Kritik der politischen Ökonomie. Erster Band. Hamburg 1890; MEGA2, vol. II/10.

${ }^{8}$ Relativamente ao Livro Segundo, cf.: Marx, Ökonomisches Manuskript 1863-1865 (MEGA ${ }^{2}$, vol. II/4.1, pp. 137-381), Ökonomische Manuskripte 1867/1868 (MEGA², vol. II/4.3), e Manuskripte zum zweiten Buch des "Kapitals". 1868 bis 1881 (MEGA², vol. II/11). Relativamente ao Livro Terceiro, cf.: Marx, Ökonomische Manuskripte. 1863-1867 (MEGA², vol. II/4.2), e Manuskripte zum dritten Buch des “Kapitals". 1871 bis 1882 $\left(\mathrm{MEGA}^{2}\right.$, vol. II/14, pp. 3-162).

${ }^{9}$ Cf. Marx, Das Kapital. Kritik der politischen Ökonomie. Zweiter Band. Hamburg 1885 (MEGA², vol. II/13) e Das Kapital. Kritik der politischen Ökonomie. Dritter Band. Hamburg 1894 (MEGA², vol. II/15).

10 “O todo está repartido em 6 Livros. 1. Do capital (contém alguns capítulos preparatórios). 2. Da propriedade fundiária. 3. Do trabalho assalariado. 4. Do Estado. 5. Comércio internacional. 6. Mercado mundial." - "Das
} 
de que aqui apenas deixo apontamento ${ }^{11}$ ).

No entanto, a partir de uma fase mais adiantada, Marx previa igualmente que - como o quarto na série - se autonomizasse "o Livro histórico-literário" (das historisch-literarische Buch) ${ }^{12}$, abarcando o estudo crítico da literatura económica: "a história da Economia Política desde os meados do século XVII" (die Geschichte der Politischen Ökonomie seit Mitte des 17. Jahrhunderts $)^{13}$. Nesta versão, o volume II reuniria o conteúdo dos Livros Segundo e Terceiro, constituindo o Livro Quarto - "a história da teoria” (die Geschichte der Theorie) - o volume III $^{14}$. Marx, na verdade, iniciou a redacção de $O$ capital - como ele próprio, aliás, reconhece - "na sequência inversa" (in der umgekehrten Reihefolge) ${ }^{15}$, começando pela parte histórica. Os Manuscritos de 1861-1863 estão, em substancial medida, dedicados ao assunto $^{16}$.

Em 1894, Engels pensava ainda poder ocupar-se em breve da edição ${ }^{17}$. Havia

Ganze ist eingeteilt in 6 Bücher. 1. Vom Kapital (enthält einige Vorchapters). 2. Vom Grundeigentum. 3.Von der Lohnarbeit. 4. Vom Staat. 5. Internationaler Handel. 6. Weltmarkt". Marx, Brief an Ferdinand Lassalle, 22. Februar 1858; MEW, vol. 29, p. 551. Na carta seguinte, a desagregação do primeiro ponto é explicitada: "1. Valor, 2. Dinheiro, 3. o capital em geral (processo de produção do capital, processo de circulação do capital, unidade de ambos ou capital e lucro, juro)." - "1. Wert, 2. Geld, 3. das Kapital im allgemeinen (Produktionsprozeß des Kapitals, Zirkulationsprozeß des Kapitals, Einheit von beiden oder Kapital und Profit, Zins)". Marx, Brief an Ferdinand Lassalle, 11 März 1858; MEW, vol. 29, p. 554. Tenha-se igualmente em conta: Marx, Brief an Engels, 2. April 1858 (MEW, vol. 29, pp. 312-318); Zur Kritik der politischen Ökonomie. Erstes Heft (1859), Vorwort (MEGA², vol. II/2, p. 99); Brief an Joseph Weydemeyer, 1. Februar1859 (MEW, vol. 29, pp. 572-573).

${ }^{11}$ Para a discussão deste tema, vejam-se, por exemplo: Henryk Grossmann, "Die Änderung des ursprünglichen Aufbauplans des Marxschen Kapital und ihre Ursachen", Archive für die Geschichte des Sozialismus und der Arbeiterbewegung, Leipzig, n. 14 (1929), pp. 305-338; Roman Rosdolsky, Zur Entstehungsgeschichte des Marxschen "Kapital". Der Rohentwurf des Kapital 1857-1858, Frankfurt am Main - Wien, Europäische Verlagsanstalt - Europa Verlag, 1968, 3 vols; Maximilien Rubel, "Introduction" (1968), O, vol. II, pp. LXXXVI-CXXVII; Vitali Solomonóvitch Wygogski, Wie "Das Kapital” entstand (1970), Berlin, Verlag Die Wirtschaft, 1976; Rubel, "Plan et méthode de l'économie" (1973), Marx critique du marxisme. Essais, Paris, Payot, 1974, pp. 369-401; Wygogski, Das Werden der ökonomischen Theorie von Marx und der wissenschaftliche Kommunismus (1975), Berlin, Dietz Verlag, 1978; Ernest Mandel, "Introduction”, 3-4, in Marx, Capital, trad. Ben Fowkes, London, Penguin Books - New Left Review, 1976, vol. I, pp. 25-38; Larissa Miskewitsch, Michail Ternowski, Alexander Tschepurenko, e Wygodski, "Zur Periodisierung der Arbeit von Karl Marx am "Kapital” in den Jahren 1863 bis 1867”, Marx-Engels Jahrbuch, Berlin, 5 (1982), pp. 294-322; Manfred Müller, "Die Bedeutung des Manuskripts "Zur Kritik der politischen Ökonomie" 1861-1863", Der zweite Entwurf des "Kapitals". Analysen, Aspekten, Argumente, ed. Wolfgang Jahn e M. Müller, Berlin, Dietz Verlag, 1983, pp. 9-41; Wolfgang Jahn, "Zur Entwicklung der Struktur des geplanten ökonomischen Hauptwerkes von Karl Marx”, Arbeitsblätter zur Marx-Engels Forschung. Martin-Luther-Universität HalleWittenberg, Halle, n. 20 (1986), pp. 6-44.

${ }^{12}$ Cf. Marx, Brief an Engels, 31. Juli 1865; MEW, vol. 31, p. 132.

${ }^{13}$ Cf. Marx, Brief an Sigfrid Meyer, 30. April 1867; MEW, vol. 31, p. 543.

${ }^{14}$ Cf. Marx, Brief an Louis Kugelmann, 13. Oktober 1866 (MEW, vol. 31, p. 534), bem como Das Kapital. Kritik der politischen Ökonomie. Erster Band. Hamburg 1867, Vorwort (MEGA ${ }^{2}$, vol. II/5, p. 14).

${ }^{15}$ Cf. Marx, Brief an Sigmund Schott, 3. November 1877; MEW, vol. 34, p. 307.

${ }^{16}$ Cf. Marx, Zur Kritik der politischen Ökonomie (Manuskript 1861-1863) Teil 2 - Teil 6; MEGA ${ }^{2}$, vols. II/3.2 II/3.6.

${ }^{17}$ Como, no prefácio do Livro Terceiro, anuncia: "Atacarei o Livro quarto - a história da teoria da mais-valia logo que, de qualquer modo, se me tornar possível." - "Das vierte Buch - die Geschichte der Mehrwerthstheorie 
elaborado já um índice dos cadernos respectivos em $1885^{18}$, e chegou mesmo a rever partes da sua transcrição ${ }^{19}$. A morte surpreendeu-o, porém, a 5 de Agosto de 1895. Embora não na sua integralidade, os manuscritos referentes às secções previstas para integrar um futuro Livro Quarto de $O$ capital, com organização editorial a cargo de Karl Kautsky, só vieram finalmente a ser publicados - sob o título de: Teorias acerca da mais-valia - em 1905 (o volume I, e os dois tomos do volume II), e em 1910 (o volume III) ${ }^{20}$.

\section{§ 2. Conteúdos}

Com um critério generoso na contabilidade, poderíamos ir, portanto, até 1910. Com contenção no rigor, de 1867 a 1894: várias são as datas de aniversário de $O$ capital, susceptíveis de efeméride. Penso, todavia, que nos devemos ater à jà referida distribuição canónica.

O capital compõe-se de três Livros. Que Marx pensou, e escreveu ${ }^{21}$. Dos quais apenas reviu e aprontou o Livro Primeiro (na forma inicial, na tradução francesa em fascículos, nas edições alemãs de 1872 e, em parte, de 1883). Mas a que, na publicação subsequente, Engels soube manter-se fiel. Na decifração de uma caligrafia "ilegível", no reconstruir da "lógica" dos desenvolvimentos. Mesmo quando seleccionou materiais, corrigiu tabelas e cálculos, procedeu a actualizações e aditamentos (de resto, como tal sempre convenientemente assinalados). Em linhas muito genéricas, como se organiza o conteúdo sumário desta obra, no seu membramento?

O Livro Primeiro examina "o processo de produção" (das Produktionsprozeß) do capital. Tanto no seu teor arquitectónico, como na sua dinâmica, aí são analisadas, entre outras questões: a mercadoria (enquanto forma objectivada de aparecimento da "riqueza"), o

\footnotetext{
- werde ich in Angriff nehmen, sobald es mir irgendwie möglich wird”. Engels, Vorwort (1894), in Marx, Das Kapital. Kritik der politischen Ökonomie. Dritter Band. Hamburg 1894; $\mathrm{MEGA}^{2}$, vol. II/15, p. 11.

${ }^{18}$ Cf. Engels, Inhaltsverzeichnis zu Marx' Manuskript 1861-1863 (1885); MEGA ${ }^{2}$, vol. II/14, pp. 345-346.

${ }^{19}$ Cf. Engels, Brief an Laura Lafargue, 28. März 1895; MEW, vol. 39, p. 450.

${ }^{20}$ Cf. Marx, Theorien über den Mehrwert. Aus dem nachgelassenen Manuskript "Zur Kritik der politischen Ökonomie”, ed. Karl Kautsky, Stuttgart, Verlag von J. H. W. Dietz Nachf., 1905 e 1910, 3 vols. em 4 tomos.

${ }^{21}$ O projecto foi, sem dúvida, desenvolvido em estreita colaboração com Engels. Desde os primórdios, como a correspondência desse período elucidativamente documenta. Após a morte de Marx, o trabalho de edição por Engels levado a cabo foi inestimável. Mas não permite atribuir-lhe a "autoria" nem dos textos, nem da concatenação fundamental do publicado. Há, por isso, exageros "sugestivos" (de certas arrecadações entretanto repescados) que, na sua imediatez treslidos, se arriscam a tomar o viso da asneira: "O tomo III de $O$ capital, que toda a tradição marxista estudou, é obra de Engels." - "El tomo III de El capital, que toda la tradición marxista estudió, es obra de Engels". Enrique Dussel, El último Marx (1863-1882) y la liberación latinoamericana. Un comentario a la tercera y cuarta redacción de "El capital" (1990), I, 2, 2.1; México, D. F. - Buenos Aires Madrid, Siglo XXI Editores, $2007^{2}$, p. 52.
} 
dinheiro (deslindado nas suas diferentes valências expressivas) ${ }^{22}$, a transformação do dinheiro em capital, o parto da mais-valia absoluta (por extensão do dia de trabalho) e da mais-valia relativa (por incremento da produtividade do trabalho), o assalariamento (que configura uma matriz do modo capitalista de produção), a incidência dos factores tecnológico-científicos (desde a maquinaria crescentemente sofisticada, até ao nível da "racionalização" dos métodos operativos), os diferenciados expedientes da acumulação do capital (incluindo a acumulação originária) e a lei que os rege.

O Livro Segundo ocupa-se do "processo de circulação" (Zirkulationsprozeß) do capital. A atenção passa a centrar-se agora, sobretudo, no movimento ${ }^{23}$. Daí, o relevo liminarmente conferido: às metamorfoses do capital (nos diferentes estádios que integram o circuito que vai descrevendo); à rotação periódica do capital nas suas formas sucessivas circulares de "dinheiro", "mercadoria", e de novo "dinheiro" (em que a velocidade desse giro não pode ver-se dissociada do desígnio reitor: a "valorização", para o capitalista, do "valor

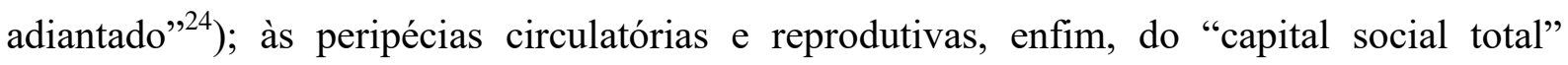
(gesellschaftliches Gesamtkapital): tanto na figura doméstica da "reprodução simples" (em que a totalidade da mais-valia é deglutida pelo consumo dos próprios capitalistas), como na

\footnotetext{
22 "Não [é] através do dinheiro [que] as mercadorias se tornam comensuráveis, [mas] inversamente. Porque todas as mercadorias, como valores, são trabalho humano objectivado - por conseguinte, [são] em si e por si comensuráveis -, elas podem medir-se todas numa qualquer mercadoria terceira, e, por isso, transformar esta [medida terceira] na medida comum de valor delas, ou dinheiro. [O] dinheiro, como medida de valor, é, porém, [a] forma fenoménica necessária da medida imanente de valor das mercadorias, do tempo de trabalho." - "Die Waaren werden nicht durch das Geld commensurabel. Umgekehrt. Weil alle Waaren als Werthe vergegenständlichte menschliche Arbeit, daher an und für sich commensurabel sind, können sie sich alle in irgend einer dritten Waare messen und diese dadurch in ihr gemeinschaftliches Werthmaß oder Geld verwandeln. Geld als Werthmaß ist aber nothwendige Erscheinungsform des immanenten Werthmaßes der Waaren, der Arbeitszeit". Marx, Das Kapital. Kritik der politischen Ökonomie. Erster Band. Hamburg 1867, I, 1,$3 ; \mathrm{MEGA}^{2}$, vol. II/ $/ 5$, p. 59.

23 "O capital, como valor que se valoriza, não encerra apenas relações de classes, um carácter social determinado que repousa sobre a existência do trabalho como trabalho assalariado. Ele é um movimento [eine Bewegung], um processo de circuito através de diversos estádios [...]. Ele apenas pode, por conseguinte, ser concebido [begriffen] como movimento, e não como coisa em repouso. Aqueles que consideram a autonomização do valor como mera abstracção esquecem que o movimento do capital industrial é essa abstracção em acto [in actu]." "Das Kapital als sich verwerthender Werth umschließt nicht nur Klassenverhältnisse, einen bestimmten gesellschaftlichen Charakter, der auf dem Dasein der Arbeit als Lohnarbeit ruht. Es ist eine Bewegung, ein Kreislaufsproceß durch verschiedne Stadien [...]. Es kann daher nur als Bewegung und nicht als ruhendes Ding begriffen werden. Diejenigen, die die Verselbständigung des Werths als bloße Abstraktion betrachten, vergessen, daß die Bewegung des industriellen Kapitals diese Abstraktion in actu ist". Marx, Das Kapital. Kritik der politischen Ökonomie. Zweiter Band. Hamburg 1885, II, I, 4; MEGA², vol. II/13, p. 98.

${ }_{24}$ "A finalidade determinante da produção capitalista é sempre [a] valorização do valor adiantado, seja este valor adiantado então ou na sua forma autónoma (quer dizer: na forma-dinheiro), ou em mercadoria, de tal modo que a sua forma de valor no preço das mercadorias adiantadas só possui autonomia ideial." - "Der bestimmende Zweck der kapitalistischen Produktion ist stets Verwerthung des vorgeschoßnen Werths, ob dieser Werth nun in seiner selbständigen Form, d. h. in der Geldform vorgeschossen sei, oder in Waare, sodaß seine Werthform im Preis der vorgeschoßnen Waaren nur ideelle Selbständigkeit besitzt”. Marx, Das Kapital. Kritik der politischen Ökonomie. Zweiter Band. Hamburg 1885, II, II, 7; MEGA², vol. II/13, p. 141.
} 
vertente expansiva da "reprodução alargada" (em que uma parcela da mais-valia é reinvestida, e se transforma, dessa maneira, em capital adicional).

O Livro Terceiro, por sua vez, cuida de recompor "o processo completo" (das Gesamtproce $\beta$ ) da produção capitalista no seu conjunto articulado. Trata-se, portanto, de compreendendo, na sua dialéctica unidade, os patamares da produção e os vectores transaccionais da actividade económica - considerar agora "o processo de movimento" (das Bewegungsproce $\beta$ ) do capital "como todo" (als Ganzes). No sentido de surpreender o embasamento, a génese, e o encadeado daquela celebérrima "fórmula trinitária" (trinitarische Formel) emparelhada - de ordinário, mal entendida - que serve de embrulho a "todos os segredos" (alle Geheimnisse) da maneira capitalista de produzir e reproduzir socialmente o viver: capital/lucro (ganho do empresário mais juros), terra/renda fundiária, trabalho/salário ${ }^{25}$.

E, neste Livro Terceiro, encontramos também diversas secções com argutos reparos no que respeita ao sistema financeiro - "o capital portador de juros" (das zinstragende Kapital) -, à lei da queda tendencial da taxa do lucro, e à renda fundiária, para além de muitas páginas interessantes sobre as crises económicas e a sua aceleração num quadro de alargamento generalizado do "sistema de crédito" (Kreditwesen), os mecanismos da concentração dos capitais, o significado efectivo das ditas "sociedades por acções" (Aktiengesellschaften), ou os desarranjos oftalmológicos (já, nessa altura, frequentes) que costumavam afectar os órgãos chorudamente remunerados pelo putativo exercício de umas funções chamadas de "supervisão" (Aufsicht): em que se recebe tanto mais, quanto menos se "veja"26.

\section{§ 3. Importância}

A importância de que $O$ capital se reveste passa certamente por todos estes aspectos. E ainda por muitos outros, que lhe vão conferindo substância determinada aos conteúdos. No entanto, ao nível da própria concepção - que comanda o estabelecimento dos problemas, e o ângulo para as abordagens -, há vectores que não podem deixar de ser postos em destaque.

\footnotetext{
${ }^{25}$ Cf. Marx, Das Kapital. Kritik der politischen Ökonomie. Dritter Band. Hamburg 1894, III, II, VII, 48; MEGA $^{2}$, vol. II/15, pp. 789-806.

${ }^{26} \mathrm{Na}$ praxe do capitalismo desenvolvido, era corrente uma mesma personalidade acumular lugares na administração de um grande número de companhias. O comentário de Marx, na sua secura, é cortante: "Os debates no Tribunal de Falências mostram que este salário de supervisão está em regra na proporção inversa da supervisão realmente exercida por estes directores nominais." - "Die Verhandlungen vor dem Bankrottgericht zeigen, daß dieser Aufsichtslohn in der Regel im ungekehrten Verhältnis steht zu der von diesen nominellen Direktoren wirklich ausgeübten Aufsicht”. Marx, Das Kapital. Kritik der politischen Ökonomie. Dritter Band. Hamburg 1894, III, V, 23; MEGA ${ }^{2}$, vol. II/15, p. 380.
} 
Até porque o desembarque de Marx na economia não aconteceu em para-quedas, nem se fez de sopetão. Teve largos, e atribulados, preparativos, que permitiram detectar-lhe a radicalidade do estatuto.

A dialéctica materialista - alcançada, como plataforma para os enfoques, após um exame crítico das representações religiosas, do idealismo filosófico em geral, da encomendação dos desígnios políticos a uma ética do "dever-ser" (Sollen) e da "harmonia" dos "sentimentos filantrópicos" - havia, com segurança desde $1845^{27}$, indicado o rumo para a viagem: "A consciência nunca pode ser outra coisa senão o ser consciente [das bewußte Sein], e o ser [das Sein] dos seres humanos é o processo [efectivamente] real de vida deles" ${ }^{\text {28 }}$. É nesta senda que, doravante, o inquérito há-de prosseguir.

$O$ capital é importante, desde logo, porque investiga pormenorizadamente "a economia" (die Ökonomie): ou seja, "o processo de produção" (der Produktionsprozeß) do viver de uma sociedade determinada, que constitui "a base material do seu mundo" (die materielle Grundlage ihrer Welt ${ }^{29}$, daquele complexo sistema de relações que ela vai pondo de pé e dentro do qual se movimenta. Não estamos - como certas almas em alvoroço escandalizadamente alvitram - perante nenhum tacanho "economicismo" desalmado, que reduz a "espiritualidade" ao cifrão. Trata-se de materialismo ontológico dialecticamente entendido, à luz do qual mesmo as "ideias" mais delicadas e subtis, que parecem levitar no seu passeio, possuem rampa de lançamento, plano de sustentação, e campo de aterragem, numa materialidade real que - ao seu modo, e da varanda em que tomam assento - reflectem, acompanham, e a que trazem perspectiva ${ }^{30}$.

\footnotetext{
${ }^{27}$ Para uma visão sucinta de outras etapas anteriores, veja-se, por exemplo, o meu estudo: "A viragem de 1844 . Engels, Marx, e a Economia Política. Uma nótula sobre primeiras abordagens", Ontologia e política - Estudos em torno de Marx II, Lisboa, Editorial “Avante!”, 2016, pp. 129-208.

28 "Das Bewußtsein kann nie etwas Andres sein als das bewußte Sein, und das Sein der Menschen ist ihr wirklicher Lebensprozeß". Marx u. Engels, Die deutsche Ideologie. Kritik der neuesten deutschen Philosophie in ihren Repräsentanten Feuerbach, B. Bauer und Stirner, und des deutschen Sozialismus in seinen verschiedenen Propheten (1845-1846), I, A; MEW, vol. 3, p. 26.

${ }^{29}$ Cf. Marx, Das Kapital. Kritik der politischen Ökonomie. Erster Band. Hamburg 1867, I, 1, 1; MEGA ${ }^{2}$, vol. II/5, p. 49.

30 “A minha investigação levou ao resultado de que [tanto] relações jurídicas como formas de Estado não são de conceber a partir delas próprias, nem a partir do chamado desenvolvimento universal do espírito humano, mas enraízam, antes, nas relações materiais de vida, cuja totalidade [Gesammtheit] Hegel - na esteira dos ingleses e dos franceses do século XVIII - resumiu sob o nome de "sociedade civil [burguesa, bürgerliche Gesellschaft]"; [levou-me ao resultado] de que, porém, a anatomia da sociedade civil é de procurar na Economia política." "Meine Untersuchung mündete in dem Ergebniß, daß Rechtsverhältnisse wie Staatsformen weder aus sich selbst zu begreifen sind, noch aus der sogenannten allgemeinen Entwicklung des menschlichen Geistes, sondern vielmehr in den materiellen Lebensverhältnisse wurzeln, deren Gesammtheit Hegel, nach dem Vorgang der Engländer und Franzosen des 18. Jahrhunderts, unter dem Namen "bürgerliche Gesellschaft" zusammenfaßt, daß aber die Anatomie der bürgerlichen Gesellschaft in der politischen Oekonomie zu suchen sei”. Marx, Zur Kritik der politischen Ökonomie. Erstes Heft (1859), Vorwort; MEGA², vol. II/2, p. 100.
} 
O capital é muito importante também, por um outro feixe articulado de razões. Designadamente:

a) Porque surpreende, no concreto das suas implicações, a historicidade inscrita no próprio modo capitalista de produção: a tratadística económica burguesa - ancestral fontanário onde as "teorias do fim da história" nem sabem que vão beber ${ }^{31}$ - gostava de apresentar "a ordem capitalista" (die kapitalistische Ordnung) como "absoluta e última figura da produção social" (absolute und letzte Gestalt der gesellschaftlichen Produktion); Marx mostra que ela tem génese, e que corresponde tão-só a "um estádio de desenvolvimento historicamente transitório" (eine geschichtlich vorübergehende Entwicklungsstufe) ${ }^{32}$.

b) Porque não se limita a descrever (e, à socapa, a consagrar) o existente naquela positividade imediata que ostenta, desligado por inteiro da dinâmica em que, apenas enquanto momento, se insere e se vai modificando. "A Economia vulgar" (die Vulgärökonomie) atémse à, e contenta-se com, "a forma fenoménica" (die Erscheinungsform) do visível que aparece - onde "as coisas, frequentemente, se expõem às avessas" (die Dinge sich oft verkehrt darstellen) do que, na verdade, são ${ }^{33}$-, ao passo que Marx cuida de descortinar "a conexão interna" (der innere Zusammenhang) que vincula o aparecente à "essência" (Wesen), a qual não é um fantasma metafísico vaporoso, mas a concreta totalidade dialéctica do processo que ele integra e onde vai assumindo figuras diferenciadas ${ }^{34}$.

c) Porque concebe a relacionalidade como um ingrediente constitutivo do real, o que obriga, numa ontologia materialista dialéctica consequente, a considerar, no próprio estatuto dos "entes", a mediação prática que trazem incorporada. O alcance desta perspectiva torna-se

\footnotetext{
${ }^{31}$ Fukuyama - que confunde, em Marx, a "pré-história" com a "história" - menciona Hegel, mas fala de Kojève: cf. Francis Fukuyama, Have we reached the end of history?, II; Santa Monica (California), Rand Corporation, 1989, pp. 2-4, e, mais tarde: The End of History and the Last Man, II, 5; London, Penguin Books, 1992, por exemplo, pp. 64-67. Marx, entretanto, já denunciara este anseio de "paralização" da história, típico da apologética do economismo burguês: "Houve história, uma vez que houve instituições de feudalidade, e que nessas instituições de feudalidade se encontram relações de produção completamente diferentes das da sociedade burguesa, que os economistas querem fazer passar por naturais e, portanto, eternas. [...]. Assim, houve história, mas não há mais." - "Il y a eu de l'histoire, puisqu'il y a eu des institutions de féodalité, et que dans ces institutions de féodalité on trouve des rapports de production tout à fait différents de ceux de la société bourgeoise, que les économistes veulent faire passer pour naturels et partant éternels. [...]. Ainsi il y a eu de l'histoire, mais il n'y en a plus". Marx, Misère de la Philosophie. Réponse à la Philosophie de la Misère de M. Proudhon (1847), II, § 7; O, vol. I, p. 89.

${ }^{32}$ Cf. Marx, Das Kapital. Kritik der politischen Ökonomie. Erster Band. Hamburg 1872, Nachwort; MEGA², vol. II/6, p. 701.

${ }^{33}$ Cf. Marx, Das Kapital. Kritik der politischen Ökonomie. Erster Band. Hamburg 1867, I, 5, 4, a; MEGA², vol. $\mathrm{II} / 5, \mathrm{p} .435$.

${ }^{34}$ Daí a observação profunda, segundo a qual: "Toda a ciência seria supérflua, se a forma fenoménica e a essência das coisas coincidissem imediatamente" - "Alle Wissenschaft wäre überflüssig, wenn die Erscheinungsform und das Wesen der Dinge unmittelbar zusammenfielen", Marx, Das Kapital. Kritik der politischen Ökonomie. Dritter Band. Hamburg 1894, III, II, VII, 48, III; MEGA², vol. II/15, p. 792.
} 
particularmente perceptível, e fecundo, na análise de inúmeros problemas em que, de ordinário, a visão "feiticista" 35 do celebrado "senso-comum" impera. Por exemplo, ao invés daquilo que habitualmente se imagina (e crê): “O capital não é uma coisa [eine Sache], mas uma relação social entre pessoas [ein gesellschaftliches Verhältniß zwischen Personen], mediada por coisas" ${ }^{\prime 36}$.

Sobremaneira, O capital é importante pela escavação de uns sítios abscônditos, onde numa semi-obscuridade de catacumba - o jazigo da "mais-valia" (Mehrwert) tem descanso permanente. Não basta reconhecer, com Adam Smith - o que não é pouco, nem para muita gente, hoje ainda, pacífico - que "o valor de qualquer mercadoria" (the value of any commodity) encontra a sua "medida real" (real measure) no "trabalho" (labour) que a produz $^{37}$, ou proclamar, com David Ricardo, que o trabalho é "a fundação de todo o valor" (the foundation of all value $)^{38}$. É preciso, na indagação, incidir em camadas mais fundas.

O segredo da marosca passa pelo "trabalho", mas só fica escancarado noutras dependências. "O sobretrabalho" (die Mehrarbeit) não é uma invenção do capitalista ${ }^{39}$, mas, no capitalismo, a forma do assalariamento apaga-lhe as feições ${ }^{40}$, que entretanto os

\footnotetext{
${ }^{35}$ O paradigma do "feiticismo" (Fetischismus) entra em cena quando "a relação social determinada dos próprios seres humanos" (das bestimmte gesellschaftliche Verhältniß der Menschen selbst) toma, para eles, "a forma fantasmagórica de uma relação entre coisas" (die phantasmagorische Form eines Verhältnisses von Dingen). Cf. Marx, Das Kapital. Kritik der politischen Ökonomie. Erster Band. Hamburg 1872, I, I, 1, 3, D, 4; MEGA², vol. II/6, p. 103.

36 "Das Kapital nicht eine Sache ist, sondern ein durch Sachen vermitteltes gesellschaftliches Verhältniß zwischen Personen”. Marx, Das Kapital. Kritik der politischen Ökonomie. Erster Band. Hamburg 1867, I, 6, 3; MEGA $^{2}$, vol. II/5, pp. 611-612.

${ }^{37}$ Cf. Adam Smith, An Inquiry into the Nature and Causes of the Wealth of Nations (1776), I, V; ed. William Letwin, London - New York, J. M. Dent \& Sons - E. P. Dutton \& Co. (Everyman's Library), 1975², vol. I, p. 26.

${ }^{38}$ Cf. David Ricardo, The Principles of Political Economy and Taxation $\left(1813,1821^{3}\right)$, I, II; ed. Donald Winch, London - New York, J. M. Dent \& Sons - E. P. Dutton \& Co. (Everyman's Library), 1973, p. 11.

39 "Como [foi] já observado, o capital não inventou o sobretrabalho. Em qualquer lugar onde uma parte da sociedade possua o monopólio dos meios de produção, o trabalhador tem que, de um modo livre ou não-livre, acrescentar, ao tempo de trabalho necessário para a sua autoconservação, um tempo de trabalho excedentário, a fim de produzir os meios de vida para os donos dos meios de produção: quer este proprietário seja um belo e bom [ $\kappa \alpha \lambda$ ò $\varsigma \kappa \dot{\alpha} \gamma \alpha \theta o ́ \varsigma]$ ateniense, um teocrata etrusco, cidadão romano [civis romanus], barão normando, detentor de escravos americano, boiardo valáquio, senhor da terra [landlord] moderno, ou [um] capitalista." "Das Kapital, wie bereits bemerkt, hat die Mehrarbeit nicht erfunden. Ueberall, wo ein Theil der Gesellschaft das Monopol der Produktionsmittel besitzt, muß der Arbeiter, frei oder unfrei, der zu seiner Selbsterhaltung nothwendigen Arbeitszeit überschüssige Arbeitszeit zusetzen, um die Lebensmittel für die Eigner der Produktionsmittel zu produzieren, ob dieser Eigenthümer nun ein athenischer $\kappa \alpha \lambda$ ò $\kappa \dot{\alpha} \gamma \alpha \theta$ ós, ein etruskischer Theokrat, civis romanus, normännischer Baron, amerikanischer Sklavenhalter, walachischer Bojar, moderner Landlord oder Kapitalist ist". Marx, Das Kapital. Kritik der politischen Ökonomie. Erster Band. Hamburg 1867, I, 3, 4; $\mathrm{MEGA}^{2}$, vol. II/5, p. 181.

40 "A forma do salário apaga, portanto, completamente, todo o vestígio da divisão do dia de trabalho em trabalho necessário [para a reposição da força de trabalho] e [em] sobretrabalho, em trabalho pago e [em trabalho] nãopago. Todo o trabalho aparece como trabalho pago. No trabalho servil [Frohnarbeit], diferenciam-se espacial e temporalmente, de modo palpavelmente sensível, o trabalho do servo para si próprio e o trabalho forçado para o seu senhor da terra. No trabalho escravo, mesmo a parte do dia de trabalho na qual o escravo apenas repõe o
} 
panegiristas de serviço fazem por esquecer. Sem cosmética, nem rodeios, a "mais-valia" corporiza "trabalho alheio não-pago" (unbezahlte fremde Arbeit) - "um excedente" (ein Überschuß) produzido pelo operário acima daquilo que como contrapartida em "salário" (Lohn) recebe ${ }^{41}$-, e que o capitalista, por ser titular jurídico da propriedade dos meios de produção, mete ao bolso sob a forma de "lucro" (Profit $)^{42}$.

As remunerações podem variar, e variam decerto, segundo outros critérios (onde a concorrência no mercado e a própria luta reivindicativa, designadamente, intervêm) ${ }^{43}$. E é imprescindível não confundir "a venda do produto" (der Verkauf des Produkts), em que, na circulação, a mais-valia "se realiza", com o processo capitalista de produção onde ela se engendra ${ }^{44}$. Mas o enigma da "exploração" (Ausbeutung, Exploitation) tem neste frenético

valor dos seus meios de vida próprios, em que ele portanto trabalha de facto para si próprio, aparece como trabalho para o amo dele. Todo o seu trabalho aparece como não-pago. No trabalho assalariado, mesmo o sobretrabalho, ou trabalho não-pago, aparece, ao invés [umgekehrt], como [trabalho] pago. [...]. Sobre esta forma fenoménica - que torna invisível a relação [efectivamente] real, e [que] mostra exactamente o contrário dela -, repousam todas as representações jurídicas do operário como do capitalista, todas as mistificações do modo capitalista de produção, todas as suas ilusões de liberdade, todas as patranhas apologéticas da Economia vulgar." - "Die Form des Arbeitslohnes löscht also jede Spur der Theilung des Arbeitstags in nothwendige Arbeit und Mehrarbeit, in bezahlte und unbezahlte völlig aus. Alle Arbeit erscheint als bezahlte Arbeit. Bei der Frohnarbeit unterscheiden sich räumlich und zeitlich, handgreiflich sinnlich, die Arbeit des Fröhners für sich selbst und die Zwangsarbeit für seinen Grundherrn. Bei der Sklavenarbeit erscheint selbst der Theil des Arbeitstags, worin der Sklave nur den Werth seiner eignen Lebensmittel ersetzt, den er in der That also für sich selbst arbeitet, als Arbeit für seinen Meister. Alle seine Arbeit erscheint als unbezahlte Arbeit. Bei der Lohnarbeit erscheint umgekehrt selbst die Mehrarbeit oder unbezahlte Arbeit als bezahlt. [...]. Auf dieser Erscheinungsform, die das wirkliche Verhälniß unsichtbar macht und grade sein Gegentheil zeigt, beruhn alle Rechtsvorstellungen des Arbeiters wie des Kapitalisten, alle Mystifikationen der kapitalistischen Produktionsweise, alle ihre Freiheitsillusionen, alle apologetischen Flausen der Vulgärökonomie". Marx, Das Kapital. Kritik der politischen Ökonomie. Erster Band. Hamburg 1867, I, 5, 4, a; MEGA², vol. II/5, p. 437.

${ }^{41}$ "Com o seu valor próprio, a força de trabalho acrescenta constantemente ao produto mais-valia: a corporização de trabalho não-pago." - "Mit ihrem eignen Werth setzt die Arbeitskraft dem Produkt beständig Mehrwerth zu, die Verkörperung unbezahlter Arbeit”. Marx, Das Kapital. Kritik der politischen Ökonomie. Zweiter Band. Hamburg 1885, II, II, 8, I; MEGA 2, vol. II/13, p. 153.

42 "Portanto, o capital não é apenas comando sobre trabalho, como A. Smith diz. Ele é, essencialmente, comando sobre trabalho não-pago. Toda a mais-valia - qualquer que seja a figura particular (de lucro, juro, renda, etc.) em que mais tarde se cristalize - é, segundo a sua substância, materialização de tempo de trabalho não-pago. $\mathrm{O}$ segredo da autovalorização do capital resolve-se em ele ter à sua disposição um quantum determinado de trabalho alheio não-pago." - "Das Kapital ist also nicht nur Kommando über Arbeit, wie A. Smith sagt. Es ist wesentlich Kommando über unbezahlte Arbeit. Aller Mehrwerth, in welcher besondern Gestalt von Profit, Zins, Rente u. s. w. er sich später krystallisire, ist seiner Substanz nach Materiatur unbezahlter Arbeitszeit. Das Geheimniß von der Selbstverwerthung des Kapitals löst sich auf in seine Verfügung über eine bestimmtes Quantum unbezahlter fremder Arbeit". Marx, Das Kapital. Ktritik der politischen Ökonomie. Erster Band. Hamburg 1867, I, 5, 3; MEGA $^{2}$, vol. II/5, p. 432.

${ }^{43}$ É neste sentido que "a regulação do dia de trabalho" (die Normirung des Arbeitstags) - que nela própria envolve "os limites do sobretrabalho" (die Grenze der Mehrarbeit) - se torna historicamente objecto de "uma luta entre o capitalista total, quer dizer: a classe dos capitalistas, e o operário total ou a classe operária" (ein Kampf zwischen dem Gesammtkapitalisten, $d . h$. der Klasse der Kapitalisten, und dem Gesammtarbeiter oder der Arbeiterklasse). Cf. Marx, Das Kapital. Kritik der politischen Ökonomie. Erster Band. Hamburg 1867, I, 3, 4; $\mathrm{MEGA}^{2}$, vol. II/5, p. 181.

${ }^{44}$ Cf. Marx, Das Kapital. Kritik der politischen Ökonomie. Zweiter Band. Hamburg 1885, II, II, 10; MEGA², vol. II/13, p. 183. "A fórmula universal do capital é D[inheiro] - M[ercadoria] - D'; quer dizer: uma soma de valor [determinada] é lançada em circulação para arrancar dela [depois] uma soma de valor maior. O processo 
"abichamento de mais-valia" (Ergatterung von Mehrwerth) ${ }^{45}$ o chafariz do qual pinga. Por conseguinte, e ao contrário do que truncadamente nos contam: "O valor de uma mercadoria [der Werth einer Waare] é igual ao valor do capital constante nela contido, mais [plus] o valor do capital variável nela reproduzido, mais o incremento [das Inkrement] desse capital variável: a mais-valia produzida" ${ }^{, 46}$.

E - para desmancho das homilias pastoris em torno da benemérita "satisfação das necessidades sociais" (dos solventes, claro está), e para descalabro da poesia heróica sobre os mitos da "criação de valor" (que, em prosa, significa: o saque da mais-valia) - o objectivo e a mola real destes empreendimentos excelsos ficam na sua nudez (muito pouco envergonhada) exibidos: “A produção capitalista não é só produção de mercadoria; ela é, essencialmente, produção de mais-valia. O operário não poduz para ele, mas para o capital. Não basta mais, por conseguinte, que ele produza em geral. Ele tem que produzir mais-valia. Só é produtivo [produktiv] o operário que produz mais-valia para o capitalista, ou que serve para a autovalorização do capital" ${ }^{, 47}$.

$\mathrm{Na}$ variante económico-tétrica das manigâncias e bruxedos para reanimação de cadáveres, sugativamente assistida: "O capital é trabalho morto [verstorbene Arbeit], que apenas se aviva - à maneira de vampiro [vampyrmäßig] - pela sucção [Einsaugung] de trabalho vivo [lebendige Arbeit], e que vive tanto mais quanto mais dele sugar" ${ }^{\text {"48 }}$.

Porque, para transformar, é conveniente compreender, $O$ capital é importante: pela compreensão que nos traz ao orientamento da incidência dos combates. A luta pelo socialismo não desemboca mais numa esgrima em torno de "valores morais": agora, sabe onde bater,

que engendra [erzeugen] esta soma de valor maior é a produção capitalista; o processo que a realiza [realisiren] é a circulação do capital." - "Die allgemeine Formel des Kapitals ist G - W - G'; d. h. eine Werthsumme wird in Cirkulation geworfen, um eine größre Werthsumme aus ihr herauszuziehen. Der Proceß, der diese größre Werthsumme erzeugt, ist die kapitalistische Produktion; der Proceß, der sie realisirt, ist die Cirkulation des Kapitals". Marx, Das Kapital. Kritik der politischen Ökonomie. Dritter Band. Hamburg 1894, III, I, I, 2; $\mathrm{MEGA}^{2}$, vol. II/15, p. 44.

${ }^{45}$ Cf. Marx, Das Kapital. Kritik der politischen Ökonomie. Zweiter Band. Hamburg 1885, II, III, 21, II; MEGA 2 , vol. II/13, p. 467.

46 "Der Werth einer Waare ist gleich dem Werth des in ihr enthaltnen konstanten Kapitals, plus dem Werth des in ihr reproducirten variablen Kapitals, plus dem Inkrement dieses variablen Kapitals, dem producirten Mehrwerths". Marx, Das Kapital. Kritik der politischen Ökonomie. Dritter Band. Hamburg 1894, III, I, II, 8; $\mathrm{MEGA}^{2}$, vol. II/15, p. 152.

47 "Die kapitalistische Produktion ist nicht nur Produktion von Waare, sie ist wesentlich Produktion von Mehrwerth. Der Arbeiter producirt nicht für sich, sondern für das Kapital. Es genügt daher nicht länger, daß er überhaupt producirt. Er muß Mehrwerth produciren. Nur der Arbeiter ist produktiv, der Mehrwerth für den Kapitalisten producirt oder zur Selbstverwerthung des Kapitals dient". Marx, Das Kapital. Kritik der politischen Ökonomie. Erster Band. Hamburg 1867,I, 5, 1; MEGA², vol. II/5, p. 413.

48 "Das Kapital ist verstorbene Arbeit, die sich nur vampyrmäßig belebt durch Einsaugung lebendiger Arbeit und so mehr lebt, je mehr sie davon einsaugt”. Marx, Das Kapital. Kritik der politischen Ökonomie. Erster Band. Hamburg 1867, I, 3, 4; MEGA $^{2}$, vol. II/5, p. 189. 
para pôr fim à apropriação privada do "mais-valor". As questões ditas "de ética" terão o seu lugar. Nas carroças do pequeno e médio "espertismo". Nos transatlânticos da trapaça. No comboio da "sobre-exploração" "49. Mas, em sentido técnico, a exploração não é sintoma de patologia "moral". É o pressuposto nuclear, e a triste condição "ontológica", de um sistema corroído: a que é possível desferir o golpe mortal.

No Anti-Dühring, Engels traduziu, com justeza, este património de novidade que desde $O$ capital nos interpela: "O socialismo até aqui criticava decerto o modo capitalista de produção subsistente e as suas consequências, mas não o podia explicar, e, portanto, também não [podia] dar cabo dele: podia apenas simplesmente rejeitá-lo como mau",50.

\section{§ 4. O sumo}

Onde reside, então, a verdadeira relevância do $O$ capital? Na suma que condensa o sumo, poderíamos porventura dizer que a importância de $O$ capital se prende com a capacidade de penetrar na arquitectura estruturante do modo capitalista de produção, de surpreender o alicerce e as dinâmicas que lhe regem o funcionamento, de discernir o feixe articulado de contradições que carrega no bojo, de lhe descompôr o halo de "perpetuidade" que gosta de aparentar (para sossego da má-consciência inquieta dos beneficiários, apaziguamento das recalcitrâncias em ascenso, e, sobremaneira, para reforço daquela perpetuação a que aspira).

A cientificidade que Marx reclama para os seus escritos económicos jamais se apresenta como higienicamente "neutra" na implicação de classe $e^{51}$. Porém, esteja-se, ou não,

\footnotetext{
${ }^{49}$ Na paleta dos gradientes, Marx também fala de "uma exploração secundária" (eine sekundäre Ausbeutung), a distinguir da "exploração original" (ursprüngliche Ausbeutung). Cf. Marx. Das Kapital. Kritik der politischen Ökonomie. Dritter Band. Hamburg 1894, III, II, V, 36, MEGA², vol. II/15, p. 599.

50 "Der bisherige Sozialismus kritisirte zwar die bestehende kapitalistische Produktionsweise und ihre Folgen, konnte sie aber nicht erklären, also auch nicht mit ihr fertig werden; er konnte sie nur einfach als schlecht verwerfen”. Engels, Herrn Eugen Dührings Umwälzung der Wissenschaft. Philosophie. Politische Ökonomie. Sozialismus (1878), Einleitung, II; MEGA ${ }^{2}$, vol. I/27, pp. 236-237.

${ }^{51}$ Em 1846, a propósito de uma projectada Kritik der Politik und Nationalökonomie, são significativos os termos em que, procurando responder às receosas apreensões do editor (Carl Friedrich Leske) com o qual contratara a publicação, reitera: "No que respeita à sua pergunta por causa da "cientificidade", eu respondi-lhe: o livro será científico, mas não [será] científico no sentido do governo prussiano" - "Was Ihre Frage wegen der "Wissenschaftlichkeit" anbelangt, antwortete ich Ihnen: Das Buch sei wissenschaftlich, aber nicht wissenschaftlich im Sinne der preußischen Regierung”, Marx, Brief an Carl Friedrich Julius Leske, 1. August 1846; $\mathrm{MEGA}^{2}$, vol. III/2, p. 22. Em 1859, depois de informar um companheiro de lutas (Joseph Weydemeyer) dos pormenores arquitectónicos da planeada Economia Política, remata: "Espero alcançar para o nosso Partido uma vitória científica." - "Ich hoffe, unsrer Partei einen wissenschaftlichen Sieg zu erringen". Marx, Brief an Joseph Weydemeyer, 1. Februar 1859; MEW, vol. 29, p. 573. Em 1872, no pós-fácio à segunda edição alemã do Livro I, a perspectiva aparece plenamente confirmada. O exame crítico da economia burguesa encontra-se,
} 
de acordo com as consequências revolucionárias que do exercício Marx retira para a luta das classes, $O$ capital constitui uma desmontagem meticulosa, fina, e fundamentada, do paradigma dominante instalado na produção e na reprodução do viver social em moldes capitalistas.

Nas condições correspondentes ao estádio de desenvolvimento à época atingido: sem dúvida, e desde logo. Mas com um alcance que transcende a mera circunscrição ao tempo em que foi redigido. Na fundamental e precisa medida em que - pela inteligência dos supostos articuladores e determinantes (não por artimanhas de adivinho) - fornece uma chave para o estudo e a decifração dos fenómenos e das transformações entretanto ocorridos no sistema, e em curso.

$O$ capital não é, pois, um livro profético, dedicado a uma vidência prognóstica (radiante, ou punitiva). Menos ainda é um pormenorizado catálogo de instrucções para a instantânea armação de aparelhos milagrosos segundo infalíveis receitas. Mas O capital configura um poderoso instrumento para a compreensão efectiva de um mundo que é possível transformar. A realidade não é nenhum monólito inteiriço - desprovido de fissura, e dotado de impenetrável fixidez inerte -, mas comporta materialmente a contradição no próprio processo em que consiste ${ }^{52}$.

E Marx mostra como, ao nível de uma inteligibilidade dialéctica do acontecer na sua verdade, "no entendimento positivo do subsistente" (in dem positiven Verständniß des Bestehenden), tem simultaneamente que estar incluído "o entendimento da sua negação" (das Verständniß seiner Negation $)^{53}$ : o pulsar daquelas potencialidades que cada existência ao dianteiro projecta.

O capital reune ingredientes teóricos inestimáveis e decisivos para uma busca de saber que, na diferença dos tempos, tem que a tempo prosseguir, em ordem a trazer luz, e horizonte, às intervenções sociais práticas que - no concreto da história - materializam

quanto ao carácter de classe, situado: "Na medida em que essa crítica represente, em geral, uma classe, ela só pode representar a classe cuja vocação [Beruf] é o revolucionamento do modo capitalista de produção e a final abolição das classes: o proletariado." - "Soweit solche Kritik überhaupt eine Klasse vertritt, kann sie nur die Klasse vertreten, deren geschichtlicher Beruf die Umwälzung der kapitalistischen Produktionsweise und die schließliche Abschaffung der Klassen ist - das Proletariat". Marx, Das Kapital. Kritik der politischen Ökonomie. Erster Band. Hamburg 1872, Nachwort; MEGA², vol. II/6, p. 703.

${ }_{52}$ Como toda a obra desdobradamente exibe e, no prefácio de 1867 , se acentua, "a sociedade actual não é nenhum cristal rígido, mas um organismo capaz de transformação [umwandlungsfähig] e constantemente compreendido no processo da transformação" - "die jetzige Gesellschaft kein fester Krystall, sondern ein umwandlungsfähiger und beständig im Prozeß der Umwandlung begriffener Organismus ist", Marx, Das Kapital. Kritik der politischen Ökonomie. Erster Band. Hamburg 1867, Vorwort; MEGA², vol. II/5, p. 14.

${ }^{53}$ Cf. Marx, Das Kapital. Kritik der politischen Ökonomie. Erster Band. Hamburg 1872, Nachwort; MEGA 2 , vol. II/6, p. 709. 
mesmo. É neste quadro, e nesta direcção usado, que o livro - como Marx, com lucidez, refere em carta a um velho militante das causas operárias (Johann Philipp Becker) - “é seguramente o míssil mais medonho [das furchtbarste Missile] que alguma vez foi disparado à cabeça dos burgueses (incluindo os proprietários fundiários)" ${ }^{\natural 54}$.

\section{§ 5. Um remate que não conclui, mas se prolonga}

Falta, no entanto, desembrulhar ainda o fardo das dificuldades. E, desde logo, começando pelo princípio. $O$ capital - na sua literalidade, nos seus desenvolvimentos, na matriz dialéctica em que é pensado e escrito - manifesta desenvencilhadamente o envencilhado de muita coisa. Mas não é um manifesto de imaginada leitura "fácil".

Em 1868, Engels redigiu um conspecto sucinto de uma parte substancial do Livro I, para provável apoio e balizagem do seu próprio estudo ${ }^{55}$. A primeira publicação só ocorreu em 1933, não constando que, anteriormente, haja circulado.

Em diferentes contextos - merecedores de pesquisa, em que aqui não entro -, várias foram as tentativas de "resumir" $O$ capital numa versão compendiada: De Johann Most em $1874^{56}$ a Edward Aveling em $1892^{57}$, passando por Carlo Cafiero ${ }^{58}$, Ferdinand Domela Nieuwenhuis $^{59}$, Gabriel Deville ${ }^{60}$, e Karl Kautsky ${ }^{61}$. Em 1912, a resenha de Deville apareceu traduzida em português, como se - a julgar pelo rosto - da obra de Marx se tratasse ${ }^{62}$.

Engels não esconde que Marx teve "muitas experiências desagradáveis" (viele unangenehme Erfahrungen $)^{63}$ com estes avulsos ensaios de "popularização", de onde malentendidos e deturpações nem sempre se encontravam ausentes da benemérita vontade de o

\footnotetext{
54 "Es ist sicher das furchtbarste Missile, das den Bürgern (Grundeigentümern eingeschlossen) noch an den Kopf geschleudert worden ist”. Marx, Brief an Johann Philipp Becker, 17. April 1867; MEW, vol. 31, p. 541.

${ }_{55}^{5}$ Cf. Engels, Konspekt über "Das Kapital” von Karl Marx. Erster Band (1868); MEW, vol. 16, pp. $243-287$.

${ }^{56}$ Cf. Johann Most, Kapital und Arbeit. Ein populärer Auszug aus "Das Kapital” von Karl Marx, Chemnitz, Im Selbstverlage des Verfassers, 1874. O texto da segunda edição (1876), contendo correcções introduzidas por Marx, figura, como apêndice, em: MEGA ${ }^{2}$, vol. II/8, pp. 733-787.

${ }^{57}$ Cf. Edward Aveling, The Students' Marx. An Introduction to the Study of Karl Marx's Capital, London, Swan Sonnenschein \& Co., 1892.

${ }^{58}$ Cf. Carlo Cafiero, Il Capitale di Carlo Marx, brevemente compendiato, Milano, Bignami e c. editori, 1879.

${ }^{59}$ Não consegui ainda ter acesso à obra. Mas Marx conhecia o texto de Nieuwenhuis - Karl Marx. Kapitaal en arbeid -, saído em 1881, e dispunha-se a sugerir-lhe algumas correcções: cf. Marx, Brief an Ferdinand Domela Nieuwenhuis, 22. Februar 1881; MEW, vol. 35, p. 159.

${ }^{60} \mathrm{Cf}$. Gabriel Deville, Le Capital de Karl Marx, résumé et accompagné d'un apperçu sur le socialisme scientifique, Paris, Henri Oriol Éditeur, 1883.

${ }^{61}$ Cf. Karl Kautsky, Karl Marx's Oekonomische Lehren. Gemeinverständlich dargestellt und erläutert, Stuttgart, Verlag von J. H. W. Dietz, 1887.

${ }^{62}$ Cf. Carlos Marx, O capital, tradução de Emília de Araújo Pereira, Lisboa, Guimarães \& C. ${ }^{a}$ Editores, 1912.

${ }^{63}$ Cf. Engels, Brief an Adolf Hepner, 25. Juli 1882; MEW, vol. 35, p. 345.
} 
traduzir numa linguagem que toda a gente entendesse.

Serve esta breve evocação para lembrar o que para alguns será desgosto. Condensações e bosquejos não estarão por completo desprovidos de utilidade. Como comentário, como introdução: no caso de estarem devidamente confeccionados. Mas a chicória mais apaladada não substitui propriamente o sabor do café. Para além de, por vezes, distorcer a afinação do paladar.

Como Marx recordava aos impacientes, numa carta que serviu de prefácio à tradução francesa de Joseph Roy, começada a sair em 1872: "Não há estrada real para a ciência, e só têm hipótese [chance] de chegar aos seus cumes luminosos aqueles que não receiam cansar-se a escalar os seus carreiros escarpados"64. Nestas matérias, não há atalho que abrevie a caminhada, nem esquemas de uma algibeira sacados que evitem o trabalho da leitura e do pensamento. A incómoda viagem pelos territórios imediatamente inóspitos tem mesmo que ser empreendida.

Na recensão de $O$ capital, que publica em 1868 no Demokratisches Wochenblatt de Leipzig, Josef Dietzgen - um curtidor de peles que, na altura, exercia o ofício em Sampetersburgo - não omite as dificuldades que sentiu, mas indica do mesmo passo, a atitude subjectiva que o animou a delas triunfar: "Aquilo que outros podem, também tu tens que poder"65. A travessia, em solitário, é possível. Mas a excursão também pode ser feita em conjunto. E com vantagem. Requer algum treino. Mas a prova não está reservada aos atletas profissionais (que, por vezes, até treinam pouco). E não é de todo uma provação apenas ao alcance da classe dos santos, dos heróis, e dos mártires.

Já o próprio Marx punha de sobreaviso contra "uma espécie de crítica" - com largo cadastro, e frequentação - "que sabe julgar [beurtheilen] e condenar [verurtheilen] o presente, mas não o [sabe] conceber [begreifen]"66. Elevar ao "conceito" (Begriff), na filosofia idealista de Hegel, é o dispositivo dialéctico da compreensão. Uma realidade contraditória só se torna inteligível num pensar capaz de dar conta da totalidade concreta e deveniente das determinações em que consiste.

Em base ontológica materialista, o "conceber" - nesta acepção dialéctica entendido -

\footnotetext{
${ }^{64}$ “Il n'y a pas de route royale pour la science, et ceux-là seulement ont chance d'arriver à ses sommets lumineux qui ne craignent pas de se fatiguer à gravir ses sentiers escarpés". Marx, Lettre au citoyen Maurice La Châtre, 18 Mars 1872; MEGA $^{2}$, vol. II/7, p. 9.

65 "Was andere können, mußt du auch können". Josef Dietzgen, "Das Kapital” von Marx. Kritik der politischen Ökonomie. Erster Band: Der Produktionsprozeß des Kapitals (1868); Gesammelte Schriften, ed. Eugen Dietzgen, Berlin, Verlag von J. H. W. Dietz Nachf., $1930^{4}$, vol. III, p. 70.

${ }^{66}$ "Eine Art von Kritik, welche die Gegenwart zu be- und verurtheilen, aber nicht zu begreifen weiß", Marx, Das Kapital. Kritik der politischen Ökonomie. Erster Band. Hamburg 1867, I, 4, 4; MEGA², vol. II/5, p. 410.
} 
é uma categoria de emprego recorrente por parte de Marx e de Engels, e com uma implicação epistemológica forte.

A advertência que mencionei dispõe, por isso, de um horizonte de respiração que não pode ser removido sem gravidade nos danos: para transformar com sentido, é preciso compreender os sentidos da realidade que requer transformação. $O$ capital é uma preciosa ajuda neste empreendimento.

Arrisco-me a dizer: não apenas pelas respostas que proporciona, mas, sobretudo, pelos elementos fundamentais que carreia para o estabelecimento fecundo das perguntas. Que, em cada etapa nova, se colocam em termos novos. Que, em qualquer momento da história, incontornavelmente nos desafiam à prática. Que é onde os respondimentos se processam. Mas é para isso que todos nós cá estamos. Mobilizando as forças de um saber enriquecido, para força acrescida dar às formas organizadas do agir que operam as transformações efectivas. Sabendo onde bater, e batendo.

Muito obrigado. 